\title{
Safety, efficacy, and pharmacokinetics of rilpivirine: systematic review with an emphasis on resource-limited settings
}

This article was published in the following Dove Press journal:

HIVIAIDS - Research and Palliative Care

28 April 20II

Number of times this article has been viewed

\author{
Nathan Ford ${ }^{1,2}$ \\ Janice Lee' \\ Isabelle Andrieux-Meyer' \\ Alexandra Calmy ${ }^{1,3}$ \\ 'Médecins Sans Frontières, Geneva, \\ Switzerland; ${ }^{2}$ Centre for Infectious \\ Disease Epidemiology and Research, \\ University of Cape Town, Cape Town, \\ South Africa; ${ }^{3}$ Service of Infectious \\ Diseases, Geneva University Hospital, \\ Geneva, Switzerland
}

\begin{abstract}
The vast majority of people living with human immunodeficiency virus (HIV)/acquired immune deficiency syndrome reside in the developing world, in settings characterized by limited health budgets, critical shortages of doctors, limited laboratory monitoring, a substantial burden of HIV in children, and high rates of coinfection, in particular tuberculosis. Therefore, the extent to which new antiretrovirals will contribute to improvements in the management of HIV globally will depend to a large extent on their affordability, ease of use, low toxicity profile, availability as pediatric formulations, and compatibility with tuberculosis and other common drugs. We undertook a systematic review of the available evidence regarding drug interactions, and the efficacy and safety of rilpivirine (also known as TMC-278), and assessed our findings in view of the needs and constraints of resource-limited settings. The main pharmacokinetic interactions relevant to HIV management reported to date include reduced bioavailability of rilpivirine when coadministered with rifampicin, rifabutin or acid suppressing agents, and reduced bioavailability of ketoconazole. Potential recommendations for dose adjustment to compensate for these interactions have not been elaborated. Trials comparing rilpivirine and efavirenz found similar outcomes up to 96 weeks in intent-to-treat analysis; failure of rilpivirine was mainly virological, whereas failure among those exposed to efavirenz was mainly related to the occurrence of adverse events. Around half of the patients who fail rilpivirine develop non-nucleoside reverse transcriptase inhibitor resistance mutations. The incidence of Grade 2-4 events was lower for rilpivirine compared with efavirenz. Grade 3-4 adverse events potentially related to the drugs were infrequent and statistically similar for both drugs. No dose-response relationship was observed for efficacy or safety, and the lowest dose $(25 \mathrm{mg}$ ) was selected for further clinical development. The potential low cost and dose of the active pharmaceutical ingredient means that rilpivirine can potentially be manufactured at a low price. Moreover, its long half-life suggests the potential for monthly dosing via nonoral routes, with promising early results from studies of a long-acting injectable formulation. These characteristics make rilpivirine an attractive drug for resource-limited settings. Future research should assess the potential to improve robustness and assess the clinical significance of interaction with antituberculosis drugs.
\end{abstract}

Keywords: rilpivirine, TMC-278, efficacy, pharmacology, safety

\section{Introduction}

Combination antiretroviral therapy has transformed the prognosis and life expectancy of people living with human immunodeficiency virus (HIV)/acquired immune deficiency

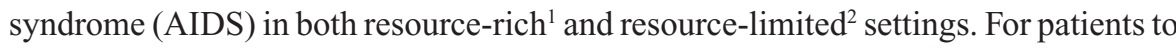
be able to benefit from these gains in the long term, antiretroviral medicines must be convenient, safe, tolerable, effective, and affordable. The main drug-related challenges to remaining on a particular regimen include side effects, interactions with other 
medications, safety during pregnancy, dosing schedules, pill burden, and degree of robustness against development of drug resistance. ${ }^{3}$

International treatment guidelines recommend using efavirenz, a non-nucleoside reverse transcriptase inhibitor (NNRTI), as part of the standard first-line regimen. Efavirenz is potent, relatively well tolerated, and easy to monitor. However, its use is limited by its low genetic barrier to development of resistance, its potential for central nervous system toxicity, concerns about safety in the first trimester of pregnancy ${ }^{4}$ and its relatively high cost. Among the alternative NNRTIs in development, rilpivirine has received attention as a potentially important drug for use in resource-limited settings because of its low manufacturing cost, its ability to be coformulated with other antiretrovirals, and its favorable safety profile.

A number of expert reviews have been published summarizing various characteristics of rilpivirine. ${ }^{5-8}$ In order to update and complement these expert reviews, we undertook a systematic review of the available evidence regarding the safety, efficacy, and pharmacokinetics of rilpivirine, and discuss here the potential implications of this drug for resource-limited settings.

\section{Search strategy}

We searched the following databases from inception to March 2011 for articles containing rilpivirine or TMC-278: Medline via PubMed, Embase, Lilics, Toxnet, and the Cochrane Central Register of Controlled Trials. We also searched the websites of major HIV conferences, ie, all international AIDS society conferences (up to Vienna, August 2010), all conferences on retroviruses and opportunistic infections (up to Boston, March 2011), and all abstracts from the international congresses on drug therapy in HIV infection (up to Glasgow, November 2010). No language restrictions were applied. We included all articles reporting original data on pharmacokinetics, tolerability, safety, and efficacy. This information was crosschecked against data presented in secondary reports (nonsystematic reviews, opinion articles, and news items). We also searched in the clinical trial.gov website to obtain information about ongoing studies. Finally, we complemented the search by reviewing bibliographies of relevant papers.

Our initial search yielded 292 articles and 31 conference abstracts. After screening out duplicates and items that did not meet our inclusion criteria, we retained six full-length articles and 16 conference abstracts. Articles comprised three clinical trials, ${ }^{9-11}$ one pharmacokinetic study, ${ }^{12}$ and two formulation studies. ${ }^{13,14}$ Conference abstracts yielded additional data from two clinical trials, ${ }^{15,16} 13$ pharmacokinetic studies, ${ }^{17-29}$ and one bioequivalence study. ${ }^{30}$ All studies were published in English.

\section{Pharmacology}

The mode of action of rilpivirine is at the stage of viral genome replication, inhibiting HIV reverse transcriptase by binding to a hydrophobic pocket near the active site of the enzyme and thus preventing transcription of viral RNA. Rilpivirine is active against HIV-1 in a variety of NNRTIresistant clinical isolates, and the relatively high potency of rilpivirine compared with the older generation of NNRTIs is thought to be due to its internal conformational flexibility ("wiggling") and the plasticity of its interaction with the binding site ("jiggling"). ${ }^{31}$

\section{Pharmacokinetics}

Rilpivirine is highly protein-bound, and more than $99 \%$ may be bound to human plasma proteins in a concentrationdependent manner. ${ }^{31}$ Under fasting conditions, the maximum plasma concentration of rilpivirine $\left(\mathrm{C}_{\max }\right)$ decreased by $46 \%$ and the area under the rilpivirine plasma concentration curve (AUC) decreased by $43 \%$. Similarly, rilpivirine $\mathrm{C}_{\max }$ and AUC are reduced by $50 \%$ when given with a protein-rich nutritional drink. ${ }^{32}$ As a consequence, it is recommended to take rilpivirine with food but avoid taking after a protein-rich drink. In a 7-day pharmacokinetic study of oral administration of rilpivirine $25 \mathrm{mg}, 50 \mathrm{mg}, 100 \mathrm{mg}$, and $150 \mathrm{mg}$ once daily, $\mathrm{C}_{\max }$ was generally reached 3-4 hours after dosing. ${ }^{32}$ Plasma concentrations were increased 2-3-fold from day 1 to day 7. Drug elimination from the plasma was slow, with a terminal half-life of 34-55 hours. ${ }^{22}$ At higher doses, there was a trend towards greater interindividual pharmacokinetic variability, but plasma concentrations did not increase proportionately with dose. A pediatric granule formulation has been developed, and its exposure under fasting conditions was comparable with the tablet formulation if taken with food (the $\mathrm{AUC}_{\infty}$ was $26 \%$ higher when taken with food ${ }^{19}$ ). The main clearance of rilpivirine is via oxidative metabolism followed by sulfate conjugation or O-glucuronidation and $\mathrm{N}$-glucuronidation in animal studies. ${ }^{32}$ Metabolic studies in human hepatocytes showed slow metabolic clearance, and $\leq 0.03 \%$ was found unchanged in the urine. ${ }^{22}$

\section{Drug-drug interactions}

The main results of drug-drug interaction studies are described below and summarized in Table 1 . 


\section{Interaction with key drugs in the management of HIV/AIDS}

Tuberculosis drugs

Two pharmacokinetic studies have investigated the interaction between rilpivirine and two drugs commonly used to treat tuberculosis, ie, rifampicin and rifabutin. Rifampicin dosed at $600 \mathrm{mg}$ once daily together with rilpivirine $150 \mathrm{mg}$ once daily was found to reduce rilpivirine $\mathrm{AUC}_{24 \mathrm{~h}}, \mathrm{C}_{\max }$, and $\mathrm{C}_{\text {min }}$ by $80 \%, 69 \%$, and $89 \%$, respectively, when given to 16 HIV-negative volunteers for 7 days. ${ }^{22}$ No significant change was seen in the pharmacokinetics of rifampicin. The study investigators concluded that concurrent administration of rilpivirine and rifampicin is not recommended.

In an 11-day study of rilpivirine $150 \mathrm{mg}$ once daily and rifabutin $300 \mathrm{mg}$ once daily in $18 \mathrm{HIV}$-negative volunteers, the $\mathrm{AUC}_{24 \mathrm{~h}}, \mathrm{C}_{\text {max }}$, and $\mathrm{C}_{\text {min }}$ of rilpivirine was reduced by $46 \%$, $35 \%$, and $49 \%$, respectively. The $\mathrm{AUC}_{24 \mathrm{~h}}$ of rifabutin and its metabolite, 25-O-desacetyl-rifabutin, were not affected by coadministration of rilpivirine. ${ }^{18}$

Both of these interactions are important for high-HIV burden settings where rates of tuberculosis/HIV coinfection are high. ${ }^{23}$ Clinical and dose-adjustment studies of rilpivirine coadministered with rifabutin or rifampicin are needed before coadministration is definitively ruled out.

\section{Antiretrovirals}

Several studies have assessed the pharmacokinetic interaction between rilpivirine and other antiretrovirals. A study of rilpivirine and tenofovir, a nucleoside reverse transcriptase inhibitor (NRTI), in 15 healthy volunteers did not show any significant difference in the exposures of both drugs. The $\mathrm{AUC}_{24 \mathrm{~h}}$ of tenofovir was increased by $24 \%$; while this increase was statistically significant, it was not considered to be clinically relevant. ${ }^{33}$ Another study looking at rilpivirine $150 \mathrm{mg}$ once daily dosed concomitantly with darunavir/ritonavir 800/100 mg once daily in 16 HIV-negative volunteers found an important increase in rilpivirine exposure $\left(\mathrm{AUC}_{24 \mathrm{~h}} 130 \%\right.$, $\left.\mathrm{C}_{\max } 79 \%, \mathrm{C}_{\min } 178 \%\right) .{ }^{29}$ Three participants discontinued the study due to Grade 2 adverse events of diarrhea and abdominal pain (one volunteer on rilpivirine alone) and enteritis and maculopapular rash (volunteers on rilpivirine and darunavir/ ritonavir). The effect of increased rilpivirine exposure when coadministered with darunavir/ritonavir was confirmed by a second study which concluded that this was due to cytochrome P450 (CYP)3A4 inhibition. ${ }^{24}$ No clinically significant change in the pharmacokinetics of darunavir/ritonavir was seen. The clinical significance of this interaction and magnitude at lower doses of rilpivirine has not been assessed.

\section{Antifungals}

Ketoconazole, an azole antifungal, is a known inhibitor of CYP3A4, and coadministration (400 mg once daily) with rilpivirine $150 \mathrm{mg}$ once daily in $16 \mathrm{HIV}$-negative volunteers resulted in an increase in $\mathrm{AUC}_{24 \mathrm{~h}}, \mathrm{C}_{\max }$, and $\mathrm{C}_{\min }$ by $49 \%$, $30 \%$, and $76 \%$, respectively, for rilpivirine. ${ }^{34}$ Conversely, the $\mathrm{AUC}_{24 \mathrm{~h}}, \mathrm{C}_{\max }$, and $\mathrm{C}_{\min }$ of ketoconazole decreased by $24 \%, 15 \%$, and $66 \%$, respectively. It is unknown if the final marketed dose of rilpivirine $25 \mathrm{mg}$ once daily warrants dose adjustment when these two drugs are coadministered.

\section{Methadone}

A modest change in the pharmacokinetics of methadone was observed when coadministered with rilpivirine $25 \mathrm{mg}$ once daily in a pharmacokinetic study involving 13 HIV-negative volunteers on dose-individualized methadone therapy. The $\mathrm{C}_{\min }, \mathrm{C}_{\max }$, and $\mathrm{AUC}_{24 \mathrm{~h}}$ of R-methadone and S-methadone were found to decrease by $24 \%, 14 \%, 16 \%$, respectively, and by $21 \%, 13 \%$, and $16 \%$, respectively. ${ }^{25}$ Rilpivirine pharmacokinetics remained within normal range in the presence of methadone. As a result of this study, clinical monitoring for methadone withdrawal symptoms is recommended because methadone maintenance therapy may need to be adjusted in some patients.

\section{Interactions with other drugs}

Both rilpivirine and atorvastatin (a HMG-CoA reductase inhibitor) are substrates of CYP3A. A study in 16 HIV-negative volunteers administered rilpivirine $150 \mathrm{mg}$ once daily and atorvastatin $40 \mathrm{mg}$ once daily found no changes in rilpivirine exposures. ${ }^{26}$ However, atorvastatin exposures were increased with the sum of atorvastatin and its two active metabolites, ie, $\mathrm{AUC}_{24 \mathrm{~h}}$ increased by $21 \%$ while $\mathrm{C}_{\max }$ increased by $35 \%$. All volunteers completed the study, with no Grade 3 or 4 adverse events reported, so no dose adjustment was recommended.

Rilpivirine is shown to have decreased solubility at increased $\mathrm{pH}$ in vitro, and coadministration of famotidine $40 \mathrm{mg}$ once daily 2 hours before rilpivirine $150 \mathrm{mg}$ once daily in a study of 24 HIV-negative subjects resulted in reduced exposures of rilpivirine $\mathrm{AUC}_{\infty}$ and $\mathrm{C}_{\max }$ by $76 \%$ and $85 \%$, respectively. ${ }^{35}$ The rilpivirine $\mathrm{AUC}_{\infty}$ was increased by $13 \%$ when famotidine was administered 4 hours after rilpivirine. No significant changes in the pharmacokinetics of either drug were noted when famotidine was administered 12 hours before rilpivirine. The conclusion of this study was that administration of acid-suppressing agents should be adequately spaced apart. 
Table I Interactions between rilpivirine and other drugs

\begin{tabular}{|c|c|c|c|c|}
\hline \multirow[t]{2}{*}{ Coadministered drug } & \multirow[t]{2}{*}{ Participants } & \multirow[t]{2}{*}{ Duration } & \multicolumn{2}{|l|}{ Dose } \\
\hline & & & Rilpivirine & Coadministered drug \\
\hline Rifabutin $^{18}$ & I8 HIV-negative volunteers & II days & $150 \mathrm{mg}$ qd & $300 \mathrm{mg}$ qd \\
\hline Rifampicin ${ }^{22}$ & I6 HIV-negative volunteers & 7 days & $150 \mathrm{mg}$ qd & $600 \mathrm{mg}$ qd \\
\hline Darunavir/ritonavir ${ }^{24}$ & 16 HIV-negative volunteers & $\begin{array}{l}\text { Session I - RIL II days } \\
\text { Session } 2 \text { - DVR/r } 22 \text { days, } \\
\text { RIL II days }\end{array}$ & $150 \mathrm{mg}$ qd & $800 \mathrm{mg} / \mathrm{l} 00 \mathrm{mg}$ qd \\
\hline Tenofovir ${ }^{33}$ & 15 healthy volunteers & $\begin{array}{l}\text { Session I - RIL } 8 \text { days } \\
\text { Session } 2 \text { - TDF } 16 \text { days, } \\
\text { RIL } 8 \text { days }\end{array}$ & $150 \mathrm{mg}$ qd & $300 \mathrm{mg}$ qd \\
\hline Atorvastatin ${ }^{26}$ & I6 HIV-negative volunteers & $\begin{array}{l}\text { Session I - Atorvastatin } 4 \text { days } \\
\text { Session } 2 \text { - RIL I } 4 \text { days, } \\
\text { atorvastatin } 4 \text { days }\end{array}$ & $150 \mathrm{mg}$ qd & $40 \mathrm{mg}$ qd \\
\hline Ketoconazole ${ }^{34}$ & 16 healthy subjects & II days & $150 \mathrm{mg}$ qd & $400 \mathrm{mg}$ qd \\
\hline Famotidine $^{35}$ & 24 HIV-negative subjects & $\begin{array}{l}\text { Famotidine administered } \\
2 \text { hours before, } 12 \text { hours before and } \\
4 \text { hours after rilpivirine }\end{array}$ & $150 \mathrm{mg} q \mathrm{~d}$ & $40 \mathrm{mg}$ qd \\
\hline Sildenafi $\left.\right|^{28}$ & $\begin{array}{l}16 \text { HIV-negative } \\
\text { male volunteers }\end{array}$ & $\begin{array}{l}\text { I } 2 \text { days RIL } 75 \mathrm{mg} \text { qd and } 50 \mathrm{mg} \text { sildenafil } \\
\text { on day } \mathrm{I} 2\end{array}$ & $75 \mathrm{mg} \mathrm{qd}$ & $50 \mathrm{mg}$ one dose \\
\hline $\begin{array}{l}\text { Ethinylestradiol } \\
\text { and norethindrone }{ }^{27}\end{array}$ & $\begin{array}{l}\text { I8 HIV-negative } \\
\text { female volunteers }\end{array}$ & 3 oral contraceptive cycles & $25 \mathrm{mg}$ qd & $\begin{array}{l}\text { Ethinylestradiol } 35 \mu \mathrm{g} \text { and } \\
\text { norethindrone I } \mathrm{mg}\end{array}$ \\
\hline Methadone $^{25}$ & I3 HIV- negative volunteers & & $25 \mathrm{mg}$ qd & $\begin{array}{l}60-100 \mathrm{mg} \text { dose } \\
\text { individualized }\end{array}$ \\
\hline
\end{tabular}

A pharmacokinetic study of 18 HIV-negative female volunteers on oral contraceptives (norethindrone $1 \mathrm{mg}$ and ethinylestradiol $35 \mu \mathrm{g}$ ) and rilpivirine (25 mg once daily) was carried out for three cycles ${ }^{27}$ and found no significant pharmacokinetic changes in any of the drugs. There was an increase of $17 \%$ in the $\mathrm{C}_{\max }$ of ethinylestradiol in the presence of rilpivirine, but this was not considered to be clinically relevant. Serum levels of progesterone, luteinizing hormone, and follicle-stimulating hormone taken on days 1 and 14 of the cycle were within normal ranges. Therefore, no dose adjustment is recommended during coadministration of rilpivirine and norethindrone/ethinylestradiol-based contraceptives.

Finally, a study assessing the pharmacokinetics of rilpivirine ( $75 \mathrm{mg}$ once daily for 12 days) when coadministered with sildenafil (50 mg on day 12) and its active metabolites found no significant change when both were coadministered in a study of 16 HIV-negative male volunteers. ${ }^{28}$

\section{Clinical efficacy}

Data on the clinical efficacy of rilpivirine have been reported from three completed trials and two ongoing trials (Table 2).

Antiviral activity and safety was established in a Phase IIa trial that randomized 47 antiretroviral-naïve adult males to rilpivirine monotherapy or placebo. In this trial, rilpivirine achieved a statistically significant median viral load reduction, and $12.1 \%$ of participants $(4 / 36)$ in the rilpivirine groups reached a viral load of $<400$ copies/mL on day 8 compared with no subjects in the placebo group. ${ }^{9}$ No changes in viral genotype or phenotype of the treated subjects were identified. 


\begin{tabular}{|c|c|c|c|c|c|c|}
\hline \multicolumn{3}{|c|}{$\begin{array}{l}\text { PK } \\
\text { Rilpivirine }\end{array}$} & \multicolumn{3}{|c|}{$\begin{array}{l}\text { PK } \\
\text { Coadministered drug }\end{array}$} & \multirow[t]{2}{*}{ Comments } \\
\hline $\mathrm{C}_{\max }$ & $\mathrm{AUC}_{24 \mathrm{~h}}$ & $\mathrm{C}_{\min }$ & $\overline{\mathbf{C}_{\max }}$ & $\mathrm{AUC}_{24 \mathrm{~h}}$ & $C_{\min }$ & \\
\hline $35 \%$ & $46 \%$ & $49 \%$ & NC & NC & NC & $\begin{array}{l}\text { Reduced rilpivirine exposure due to } \\
\text { CYP3A4 induction by rifabutin }\end{array}$ \\
\hline $69 \%$ & $80 \%$ & $89 \%$ & NC & NC & NC & $\begin{array}{l}\text { Reduced rilpivirine exposure due } \\
\text { to CYP3A4 induction by rifampicin }\end{array}$ \\
\hline$\uparrow 79 \%$ & $\uparrow 130 \%$ & $\uparrow । 78 \%$ & $10 \%$ & $11 \%$ & $11 \%$ & $\begin{array}{l}\text { Increased rilpivirine exposure } \\
\text { due to CYP3A4 inhibition; the } \\
\text { increase is not clinically relevant } \\
\text { and no dose modification is } \\
\text { recommended }\end{array}$ \\
\hline $3 \%$ & $\uparrow 2 \%$ & NC & $\uparrow 21 \%$ & $\uparrow 24 \%$ & $\uparrow 24 \%$ & $\begin{array}{l}\text { Increase in TDF exposure is not } \\
\text { clinically relevant and no dose } \\
\text { modification is recommended }\end{array}$ \\
\hline NC & NC & NC & $\uparrow 35 \%$ & $\begin{array}{l}\uparrow 21 \% \text { (total HMG-CoA } \\
\text { reductase activity) }\end{array}$ & NC & No dosage adjustment needed \\
\hline$\uparrow 30 \%$ & $\uparrow 49 \%$ & $\uparrow 76 \%$ & $15 \%$ & $24 \%$ & $66 \%$ & $\begin{array}{l}\text { Increased RIL exposure due to } \\
\text { CYP3A4 inhibition by } \\
\text { ketoconazole }\end{array}$ \\
\hline $\begin{array}{l}85 \% \\
\text { ( } 2 \text { hours } \\
\text { before) }\end{array}$ & $\begin{array}{l}\text { AUC }_{\infty} 76 \% \\
(2 \text { hours } \\
\text { before })\end{array}$ & $?$ & NC & NC & NC & $\begin{array}{l}\text { Acid suppressing agent such as } \\
\text { famotidine reduce bioavailability } \\
\text { of RIL and therefore should be } \\
\text { adequately space apart when given } \\
\text { together }\end{array}$ \\
\hline NC & NC & NC & NC & NC & NC & No dosage adjustment needed \\
\hline NC & NC & NC & $\begin{array}{l}\text { EST: } \uparrow I 7 \% \\
\text { NE: NC }\end{array}$ & $\begin{array}{l}\text { EST: NC } \\
\text { NE: NC }\end{array}$ & $\begin{array}{l}\text { EST: NC } \\
\text { NE: NC }\end{array}$ & No dosage adjustment needed \\
\hline NC & $\mathrm{NC}$ & NC & $\begin{array}{l}\text { R-methadone: } 14 \% \\
\text { S-methadone: } 13 \%\end{array}$ & $\begin{array}{l}\text { R-methadone: } 16 \% \\
\text { S-methadone: } 16 \%\end{array}$ & $\begin{array}{l}\text { R-methadone: } 24 \% \\
\text { S-methadone: } 21 \%\end{array}$ & $\begin{array}{l}\text { Clinical monitoring for methadone } \\
\text { withdrawal symptoms is } \\
\text { recommended }\end{array}$ \\
\hline
\end{tabular}

Abbreviations: $\mathrm{AUC}_{24}$, area under the curve over 24 hours; $A \cup C_{\infty}$, area under the curve zero to infinity; $C_{\text {max }}$, maximum concentration; $C_{\text {min }}$, minimum concentration; DRV, darunavir; EST, ethinylestradiol; NE, norethindrone; NC, no change; P, pharmacokinetics; qd, once daily; RIL, rilpivirine; TDF, tenofovir.

This study was followed by a Phase II open-label trial evaluating the antiviral activity of rilpivirine administered at three different doses $(25 \mathrm{mg}, 50 \mathrm{mg}$, or $150 \mathrm{mg})$ replacing either the protease inhibitor or an NNRTI of an ongoing failing treatment regimen. ${ }^{10}$ In this nonrandomized, noncomparative trial, 36 patients were assessed for short-term (7-day) changes in viral load. Overall, the median change from baseline was $-1.19 \log _{10}$ copies/ $\mathrm{mL}$ in the protease inhibitor-substituted therapy group and $-0.71 \log _{10}$ copies/mL in the NNRTI-substituted therapy group, demonstrating that rilpivirine has significant antiviral activity against HIV-1 in treatment-experienced patients.

A large, randomized Phase IIb dose-ranging study that compared the antiviral activity of rilpivirine $(25 \mathrm{mg}$, $75 \mathrm{mg}$, or $150 \mathrm{mg}$ ) and efavirenz administered as triple therapy in treatment-naïve patients at 48 weeks and 96 weeks found no statistically significant difference in viral suppression or CD4 gain. ${ }^{11}$ Virological failure was similar for both groups ( $6 \%$ for rilpivirine vs $7 \%$ for efavirenz). The proportion of patients developing treatment-emergent NNRTI resistance-associated mutations was similar between the groups.

Finally, in a large pooled analysis of two ongoing randomized Phase III trials (1368 patients) rilpivirine showed noninferior efficacy compared with efavirenz at 48 weeks. ${ }^{15}$ Virological failure was higher in the rilpivirine group ( $9 \%$ vs $4.8 \%$ ), while the incidence of adverse events leading to trial discontinuation was higher in the efavirenz group ( $8 \%$ vs $3 \%$ ). A difference in virologic response favoring efavirenz was noted for patients in whom HIV RNA was $>100,000$ copies at study initiation. An effect 


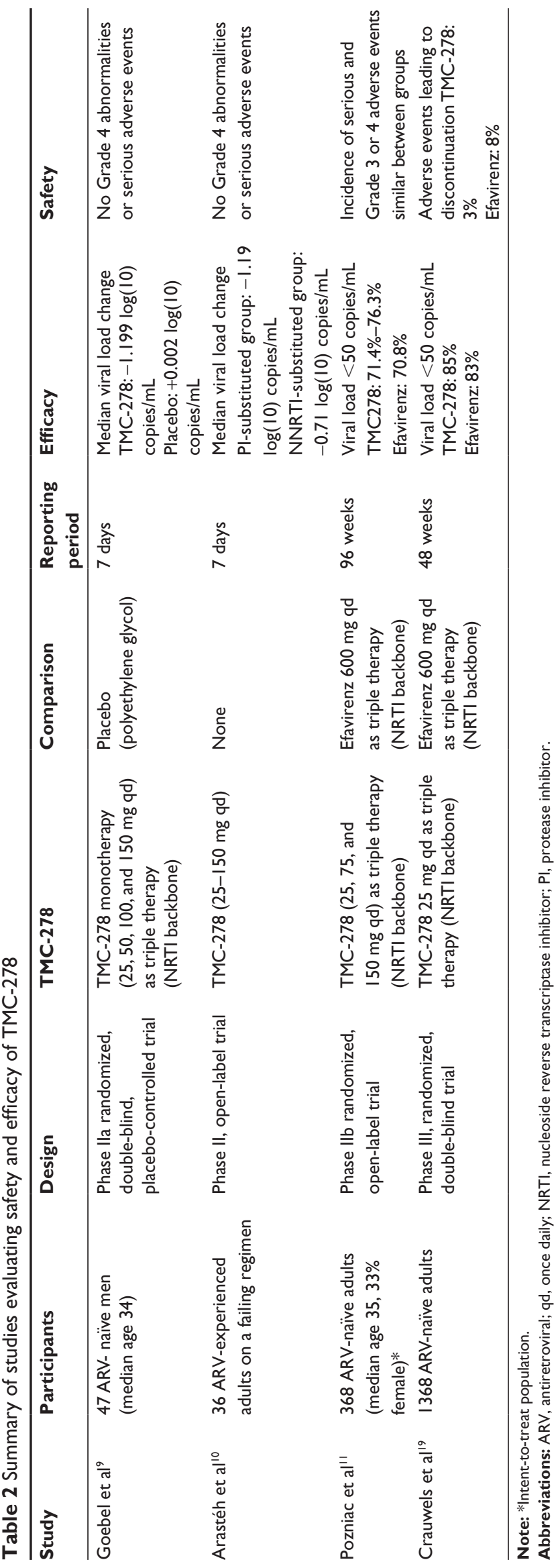

of low-dose rilpivirine could not be excluded in the intent-to-treat analysis, in which discontinuation due to adverse events, death, and other reasons, was considered as failure. Failure on rilpivirine was due to virological failure, exposing patients to resistant mutations both for NNRTI and for NRTI, whereas failure among those exposed to efavirenz was related to the occurrence of adverse events, with no risk for compromising future treatment options. Among successfully genotyped patients, $68 \%$ of patients exposed to rilpivirine and $32 \%$ of patients exposed to efavirenz had emergent NRTI mutations, the most frequent NRTI mutation with rilpivirine being M184I (the lamivudine/emtricitabine mutation that often precedes and is replaced by M184V). Rates of emerging NNRTI-related mutations were similar between the two groups ( $50 \%$ for rilpivirine vs $43 \%$ for efavirenz). The most frequent NNRTI mutation to emerge upon rilpivirine failure was E138K, a mutation associated with resistance to etravirine, efavirenz, and nevirapine in vitro, whereas the K103N was most frequent for efavirenz. ${ }^{16}$ This trial is planned to continue through to 96 weeks.

Further studies underway include a comparison of the safety, efficacy, and tolerability of rilpivirine in adolescents (Clinical trials.gov identifier: NCT0799864), a Phase III trial to evaluate the new combination of tenofovir/emtricibitane and rilpivirine as a fixed-dose combination in treatmentnaïve patients (NCT00540449), and two trials to evaluate switching from regimens consisting of a ritonavir-boosted protease inhibitor and two NRTIs or efavirenz and two NRTIs to a fixed-dose combination of emtricitabine, rilpivirine, and tenofovir (NCT01252940, NCT01286740). A bioavailability study in healthy adult volunteers to evaluate three pediatric formulations of rilpivirine (a solution, a suspension, and granules) compared with an adult tablet formulation has recently been completed (Trial NCT00812292), but has yet to be reported.

\section{Safety and tolerability}

The most extensive safety and tolerability data to date come from the 96-week Phase IIb trial, in which the median duration of follow-up extended to over 100 weeks. ${ }^{11}$ This study reported that rilpivirine was safe and well tolerated across a range of doses from $25 \mathrm{mg}$ to $150 \mathrm{mg}$.

The overall incidence of Grade 2-4 events potentially related to the drug was lower for patients receiving rilpivirine compared with efavirenz $(20.4 \%$ vs $37.1 \%$, $P=0.003)$. Events included nausea, dizziness, abnormal dreams/nightmare, dyspepsia, asthenia, rash, somnolence, and vertigo. None of these events were reported in more 
than $4 \%$ of patients, and all were less frequently reported in patients receiving rilpivirine compared with efavirenz. Incidence of Grade 2-4 rash was also statistically significantly lower among patients randomized to rilpivirine $(3.2 \%$ versus $11.2 \%, P<0.05)$.

Grade 3 or 4 adverse events potentially related to the drugs were infrequent and statistically similar $(5.4 \%$ for rilpivirine and $7.9 \%$ for efavirenz). Grade 3 or 4 laboratory abnormalities in hemoglobin occurred in $2.2 \%$ of patients, and all were in the rilpivirine groups. However, hemoglobin levels declined for all groups, and recovered throughout the course of the trial, returning to baseline levels in all groups and even increasing above baseline at week 96. Incident anemia developed predominantly in the subgroup of patients using zidovudine/lamivudine as the NRTI backbone. ${ }^{11}$

Incidence of serious adverse events was similar at $12.2 \%$ for rilpivirine and $14.6 \%$ for efavirenz. Events considered at least possibly related to study medication occurred in one patient receiving efavirenz (arthralgia) and five patients receiving rilpivirine (aspartate aminotransferase/alanine aminotransferase increase/cytolytic hepatitis, blood amylase increase, abdominal pain/constipation, attempted suicide, and anemia).

There were no consistent or clinically relevant changes in vital signs among patients on rilpivirine. Increases in QT interval had been observed at week 48 with all rilpivirine doses and with efavirenz, but these changes stabilized from week 48 onwards. This increase was seen in patients receiving zidovudine/lamivudine, but not with tenofovir/ emtricitabine. ${ }^{11}$ The smallest increases to $\mathrm{QT}_{\mathrm{c}}$ were observed with the $25 \mathrm{mg}$ rilpivirine dose. ${ }^{29,36}$ The clinical significance of the $\mathrm{QT}_{\mathrm{c}}$ prolongation in patients with and without established cardiac conditions is not known.

Further evidence of the side effect profiles of rilpivirine and efavirenz comes from the 48 -week interim pooled analysis of the two ongoing Phase III trials. ${ }^{15}$ In this analysis, rilpivirine resulted in fewer discontinuations for adverse events and fewer instances of neurologic and psychiatric adverse events, lipid elevations, and rash, compared with efavirenz (Table 3). In view of similar efficacy and safety across treatment arms, the $25 \mathrm{mg}$ dose was selected for Phase III development.

Safety in pregnancy has not been directly assessed because pregnant women are excluded from clinical trials, in keeping with prevailing ethical norms. However, studies in rats and rabbits have not found any adverse effect of rilpivirine on fertility, embryonic development, prenatal and postnatal development, or the immune system. ${ }^{37}$ To date,
Table 3 Summary of adverse event data from Phase III trials ${ }^{15}$

\begin{tabular}{llll}
\hline & $\begin{array}{l}\text { TMC-278 } \\
\text { (686 patients) }\end{array}$ & $\begin{array}{l}\text { Efavirenz } \\
\text { (682 patients) }\end{array}$ & P value \\
\hline $\begin{array}{l}\text { Median treatment } \\
\text { duration, weeks }\end{array}$ & 56 & 56 & \\
$\begin{array}{l}\text { Grade 2-4 adverse } \\
\text { events (\%) }\end{array}$ & 16 & 31 & $<0.000$ I \\
$\begin{array}{l}\text { Discontinuation due } \\
\text { to adverse events }\end{array}$ & 3 & 8 & 0.0005 \\
$\begin{array}{l}\text { Most common adverse events } \\
\begin{array}{l}\text { Any neurological } \\
\text { adverse events }\end{array}\end{array}$ & 17 & 38 & \\
$\begin{array}{l}\text { Dizziness } \\
\text { Any psychiatric } \\
\text { adverse events }\end{array}$ & 8 & 26 & $<0.000$ I \\
$\begin{array}{l}\text { Abnormal dreams } / \\
\text { nightmares }\end{array}$ & 8 & 23 & $<0.000$ I \\
Rash (any type) & 3 & 13 & 0.0002 \\
\hline
\end{tabular}

there are no published data on the incidence of lipodystrophy in patients exposed to rilpivirine.

\section{Perspectives for resource-limited settings}

The choice of preferred antiretroviral drug regimens in resource-limited settings depends on a number of characteristics and constraints common to these settings. First, regimens must be efficient and robust. Second, the regimens must be as affordable as possible. Third, because care is mainly provided at the primary care level by lesser-trained health workers with minimal laboratory monitoring, they must have minimal side effects. Fourth, they should be compatible with other commonly used drugs, in particular tuberculosis medications. Fifth, they should be safe and effective for patient groups that are more commonly in need in resource-limited settings, in particular women of childbearing age and children. Finally, they should be available as fixed-dose combinations to maximize adherence. ${ }^{4}$ Rilpivirine has some, but not all, of these characteristics.

Clinical trial data reported to date demonstrate good efficacy, but the fact that around half of patients who fail rilpivirine develop NNRTI resistance mutations is a cause for concern.

The cost of the active pharmaceutical ingredients of antiretroviral drugs can account for between 5\%-99\% of direct manufacturing costs. ${ }^{38}$ In the case of rilpivirine, the active pharmaceutical ingredient can be manufactured at a very low price, as low as \$US10 per patient/year. The lower dosage also allows for coformulation with other drugs.

A fixed-dose of rilpivirine, emtricitabine, and tenofovir has been evaluated and found to have comparable bioequivalence 
with the individual drugs. ${ }^{30}$ For resource-limited settings, the combination of rilpivirine, lamivudine, and tenofovir could potentially cost at least one-third less than the alternative combination of efavirenz, lamivudine, and tenofovir (US\$114 vs US\$ 176 per patient/year). ${ }^{39}$ However, current licensing arrangements for generic manufacture are too restrictive because they are limited to specific companies and exclude a number of high HIV-burden countries, ${ }^{40}$ including South Africa and Brazil, which account for a substantial proportion of the total number of people receiving antiretroviral therapy in low-income and middle-income countries. ${ }^{41}$ In order to facilitate the development of fixed-dose combinations and encourage reduced prices through increased competition, a number of international agencies, including the World Health Organization, the Joint United Nations Programme on HIV/ AIDS, and the Médecins Sans Frontières, have called for the inclusion of rilpivirine into the Medicines Patent Pool. ${ }^{42}$

The long half-life of rilpivirine suggests a potential for monthly dosing via nonoral formulations. An injectable nanosuspension of rilpivirine has been developed and showed a promising pharmacokinetic profile in both animals and humans. ${ }^{12,17}$ A $600 \mathrm{mg}$ intramuscular injection was found to result in sustained release of rilpivirine, and simulation of the pharmacokinetic profile predicted a oncemonthly delivery similar to oral dosing with $25 \mathrm{mg}$ once daily. ${ }^{17}$ Unfortunately, a clinical trial aimed at determining the safety, tolerability, and long-term plasma exposure over time of a one-dose regimen of four monthly subcutaneous doses of a long-acting formulation of rilpivirine (NCT00741741) has been terminated prematurely, although the results of this trial have yet to be placed in the public domain. The benefit of such a long-acting formulation in terms of adherence would depend on coadministration with other drugs that could be administered at similar intervals. Drugs currently in development that show potential for combination with rilpivirine in a long-acting formulation include GSK-572, GSK-744, CMX-157, and elvucitabine (although currently no further clinical development is planned for the latter drug).

The clinical efficacy of the lowest drug dose has to be proven over the long term. Trial data suggest that use of rilpivirine in patients with high viral load at treatment initiation may be precluded. ${ }^{15}$ The side effect profile of rilpivirine is at least equivalent to and potentially even better than nevirapine and efavirenz, the two most common antiretroviral medications used in resource-limited settings. ${ }^{15}$

However, the safety and efficacy of rilpivirine in specific patient groups remains to be evaluated. No studies have yet been undertaken to assess rilpivirine in children under 12 years of age, although a bioavailability study evaluating a solution, suspension, and granules compared with adult rilpivirine tablets has been completed (NCT00812292).

\section{Rilpivirine as prevention, treatment, or both?}

Several recent studies have demonstrated the potential for antiretrovirals in preventing HIV infection. One study (the Pre-Exposure Prophylaxis Initiative [IPreX]) found that men who have sex with men taking daily tenofovir/emtricitabine as pre-exposure prophylaxis were $44 \%$ less likely to become HIV-infected compared with those taking placebo. ${ }^{43}$ The good tolerability of oral tenofovir as pre-exposure prophylaxis among men who have sex with men was confirmed by a second study (CDC-4323), ${ }^{44}$ while a third study (Center for the AIDS Program of Research in South Africa [CAPRISA] 004) demonstrated that tenofovir applied as a vaginal gel reduced the risk of contracting HIV by $39 \%$ in women. ${ }^{45}$

Antiretroviral medications such as rilpivirine that can be administered as long-acting formulations have particular interest as prevention interventions because they provide the potential for weekly or monthly administration. This advantage is evident from the results of the IPreX trial, in which poor adherence to daily tenofovir treatment compromised the overall effect size of the trial. A preclinical evaluation of the potential prophylactic application of rilpivirine at a range of intervals would be the logical first step.

There are also broader considerations. The use of any antiretroviral as pre-exposure prophylaxis will require administering these drugs to many more people than for treatment alone, and this raises a number of ethical concerns, including fair allocation (who is prioritized for pre-exposure prophylaxis, and who will pay), and the potential for speeding up the development of resistance to drugs used for pre-exposure prophylaxis, which may lead to recommendations to withhold a drug with preventive potential from being used in treatment. ${ }^{46}$ Given the potential usefulness of rilpivirine as both prevention and treatment, careful consideration will be needed in order to ensure that this drug is used to the greatest benefit.

\section{Conclusion}

The vast majority of people living with HIV/AIDS reside in the developing world, in settings characterized by limited health budgets, critical shortages of doctors, limited laboratory monitoring, a substantial burden of pediatric HIV, and high rates of coinfection, in particular with tuberculosis. Therefore, the extent to which new antiretrovirals will 
contribute to improvements in the management of HIV globally will depend to a large extent on their affordability, ease of use, limited toxicity, pediatric formulations, and compatibility with tuberculosis and other drugs that are commonly prescribed for people living with HIV/AIDS.

The development of rilpivirine to date has taken many, but not all, of these issues into account. Overall, the low dose (allowing for low cost and coformulation), good efficacy and safety profile, and potential for formulation in fixed-dose combinations, and ongoing development of pediatric formulations, makes rilpivirine an attractive drug for resourcelimited settings. Disadvantages of this drug include limited robustness and important potential drug-to-drug interactions, in particular with antituberculosis drugs. Future research should consider the potential for increasing robustness without increasing toxicity using higher doses, the clinical significance of the interaction between rilpivirine and tuberculosis drugs, and the safety and efficacy of pediatric formulations. Finally, policies are needed to overcome intellectual property barriers to the development of fixed-dose combinations and to ensure access and affordability for all people living with HIV/AIDS.

\section{Disclosure}

The authors report no conflicts of interest in this work.

\section{References}

1. Hogg R, Lima V, Sterne JA, et al; Antiretroviral Therapy Cohort Collaboration. Life expectancy of individuals on combination antiretroviral therapy in high-income countries: A collaborative analysis of 14 cohort studies. Lancet. 2008;372(9635):293-299.

2. Mills E, Bakanda C, Chan K, et al; for the TASO-CAN group. Life expectancy of individuals on combination antiretroviral therapy in Uganda: a cohort analysis of more than 23,000 patients. Abstract TUPE0212, presented at the XVIII International AIDS Conference, July 18-23, 2010, Vienna, Austria.

3. Mills EJ, Nachega JB, Bangsberg DR, et al. Adherence to HAART: A systematic review of developed and developing nation patient-reported barriers and facilitators. PLoS Med. 2006;3(11):e438.

4. Ford N, Mofenson L, Kranzer K, et al. Safety of efavirenz in firsttrimester of pregnancy: A systematic review and meta-analysis of outcomes from observational cohorts. AIDS. 2010;24(10):1461-1470.

5. Garvey L, Winston A. Rilpivirine: A novel non-nucleoside reverse transcriptase inhibitor. Expert Opin Investig Drugs. 2009;18(7):1035-1041.

6. Adams J, Patel N, Mankaryous N, Tadros M, Miller CD. Nonnucleoside reverse transcriptase inhibitor resistance and the role of the secondgeneration agents. Ann Pharmacother. 2010;44(1):157-165.

7. Hughes CA, Robinson L, Tseng A, MacArthur RD. New antiretroviral drugs: A review of the efficacy, safety, pharmacokinetics, and resistance profile of tipranavir, darunavir, etravirine, rilpivirine, maraviroc, and raltegravir. Expert Opin Pharmacother. 2009;10(15):244-266.

8. Miller CD, Crain J, Tran B, Patel N. Rilpivirine: A new addition to the anti-HIV-1 armamentarium. Drugs Today (Barc). 2011;47(1):5-15.

9. Goebel F, Yakovlev A, Pozniak AL, et al. Short-term antiviral activity of TMC278 - a novel NNRTI - in treatment-naive HIV-1-infected subjects. AIDS. 2006;20(13):1721-1726.
10. Arastéh K, Rieger A, Yeni P, et al. Short-term randomized proofof-principle trial of TMC278 in patients with HIV type-1 who have previously failed antiretroviral therapy. Antiviral Ther. 2009;14(5): 713-722.

11. Pozniak AL, Morales-Ramirez J, Katabira E, et al. Efficacy and safety of TMC278 in antiretroviral-naive HIV-1 patients: Week 96 results of a phase IIb randomized trial. AIDS. 2010;24(1):55-65.

12. Van't Klooster G, Hoeben E, Borghys H, et al. Pharmacokinetics and disposition of rilpivirine (TMC278) nanosuspension as a long-acting injectable antiretroviral formulation. Antimicrob Agents Chemother. 2010;54(5):2042-2050.

13. Baert L, van't Klooster G, Dries W, et al. Development of a long-acting injectable formulation with nanoparticles of rilpivirine (TMC278) for HIV treatment. Eur J Pharm Biopharm. 2009;72(3):502-508.

14. Van Gyseghem E, Pendela M, Baert L, et al. Powder for reconstitution of the anti-HIV-1 drug TMC278 - formulation development, stability and animal studies. Eur J Pharm Biopharm. 2008;70(3):853-860.

15. Cohen C, Molina JM, Cahn P, et al. Pooled week 48 safety and efficacy results from the ECHO and THRIVE phase III trials comparing TMC278 vs EFV in treatment-naïve, HIV-1-infected patients. Abstract 048, presented at the Tenth International Congress on Drug Therapy in HIV Infection, November 7-11, 2010, Glasgow, Scotland.

16. Rimsky L, Eron J, Clotet B, et al. Characterization of the resistance profile of TMC278: 48-week analysis of the phase 3 studies ECHO and THRIVE. Abstract H-1810, presented at the 50th Interscience Conference on Antimicrobial Agents and Chemotherapy. September 12-15, 2010, Boston, MA.

17. Verloes R, van't Klooster G, Baert L, et al. TMC278 long acting a parenteral nanosuspension formulation that provides sustained clinically relevant plasma concentrations in HIV-negative volunteers. Abstract TUPE0042, presented at the XVII International AIDS Conference, August 3-8, 2008, Mexico City, MX.

18. Crauwels H, van Heeswijk R, Kestens D, et al. The pharmacokinetic (PK) interaction between rifabutin and TMC278, an investigational non-nucleoside reverse transcriptase inhibitor (NNRTI). Abstract TUPE0080, presented at the XVIIth International AIDS Conference, August 3-8, 2008, Mexico City, MX.

19. Crauwels H, van Heeswijk R, McNeeley D, et al. Relative bioavailability of a concept paediatric formulation of TMC278, an investigational NNRTI. Abstract TUPE0158, presented at the XVIIIth International AIDS Conference, July 18-23, 2010, Vienna, Austria.

20. Hoetelmans R, Kestens D, Marien K, et al. Effect of food and multiple dose pharmacokinetics of TMC278 as an oral tablet formulation. Abstract TuPe3.1B10, presented at the Third International AIDS Society Conference on HIV Pathogenesis and Treatment, July 24-27, 2005, Rio de Janeiro, Brazil.

21. De Béthune M-P, Andries K, Azijin H, et al. TMC278, a new potent NNRTI, with an increased barrier to resistance and favourable pharmacokinetic profile. Poster 556, presented at the 12th Conference on Retroviruses and Opportunistic Infections, February 22-25, 2005, Boston, MA.

22. Van Heeswijk R, Hoetelmans RMW, Kestens D, et al. The effects of CYP3A4 modulation on the pharmacokinetics of TMC278, an investigational non-nucleoside reverse transcriptase inhibitor (NNRTI). Poster 74, presented at the Seventh International Workshop of Clinical Pharmacology, April 20-22, 2006, Lisbon, Portugal.

23. Chamie G, Luetkemeyer A, Charlebois E, Havlir DV. Tuberculosis as part of the natural history of HIV infection in developing countries. Clin Infect Dis. 15;50 (Suppl 3):S245-S254.

24. Van Heeswijk R, Hoetelmans RMW, Kestens D, et al. The pharmacokinetic interaction between TMC 278, a next generation NNRTI, and once-daily darunavir/ritonavir in HIV negative volunteers. Presented at the 47th Interscience Conference on Antimicrobial Agents and Chemotherapy, September 17-20, 2007, Chicago, IL.

25. Crauwels H, van Heeswijk R, Vandevoorde A, et al. Pharmacokinetic interaction study between TMC278, a next-generation NNRTI, and methadone. Abstract WEPE0089, presented at the XVIII International AIDS Conference, July 18-23, 2010, Vienna, Austria. 
26. Van Heeswijk RPG, Hoetelmans RMW, Aharchi F, et al. The pharmacokinetic interaction between atorvastatin and TMC278, a next-generation non-nucleoside reverse transcriptase inhibitor, in HIV-negative volunteers. Presented at the 11th European AIDS Conference, October 24-27, 2007, Madrid, Spain.

27. Crauwels H, van Heeswijk R, Cornelis L, et al. Pharmacokinetic interaction study between TMC278, an NNRTI, and the contraceptives norethindrone plus ethinylestradiol. Presented at the 12th European AIDS Conference, November 11-14, 2009, Cologne, Germany.

28. Crauwels H, van Heeswijk R, Stevens M, et al. TMC278, a nextgeneration NNRTI, does not alter the pharmacokinetics of sildenafil. Abstract presented at the 10th International Workshop on Clinical Pharmacology of HIV, April 15-17, 2009, Amsterdam, the Netherlands.

29. Santoscoy M, Cahn P, Gonsalez C, et al. TMC278 (rilpivirine), a next-generation NNRTI, demonstrates long-term efficacy and tolerability in ARV-naïve patients: 96-week results of study C204. Abstract TUAB0103, presented at the XVIIth International Aids Conference, August 3-8, 2008, Mexico City, MX.

30. Mathias AMM, Wei X, Dave A, et al. Bioequivalence of the co-formulation of emtricitabine/rilpivirine/tenofovir DF. Abstract LBPE17, presented at the XVIII International AIDS Conference, July 18-23, 2010, Vienna, Austria.

31. Janssen PA, Lewi PJ, Arnold E, et al. In search of a novel anti-HIV drug: Multidisciplinary coordination in the discovery of 4-[[4-[[4-[(1E)-2cyanoethenyl]-2,6-dimethylphenyl]amino]-2- pyrimidinyl]amino]benzonitrile (R278474, rilpivirine). J Med Chem. 2005;48(6):1901-1909.

32. Crauwels HM, van Heeswijk R, Bollen A, et al. The effect of different types of food on the bioavailability of TMC278, an investigational NNRTI. Poster presented at the Ninth International Workshop on Pharmacology of HIV Therapy, April 7-9, 2008, New Orleans, LA.

33. Hoetelmans R, Kestens D, Stevens M, et al. Pharmacokinetic interaction between the novel non-nucleoside reverse transcriptase inhibitor (NNRTI) TMC278 and tenofovir fumarate (TDF) in healthy volunteers. Poster 18, presented at the Sixth International Workshop on Clinical Pharmacology of HIV Therapy, April 28-30, 2005, Quebec City, QC.

34. Van Heeswijk R, Hoetelmans RM, Kestens D, et al. The pharmacokinetic interaction between ketoconazole and TMC278, an investigational non-nucleoside reverse transcriptase inhibitor (NNRTI), in healthy HIV-negative subjects. Abstract TUPE0087, presented at the XVI International AIDS Conference, August 13-18, 2006, Toronto, ON.

35. Van Heswijk R, Hoetelmans RM, Kestens D, et al. The pharmacokinetic (PK) interaction between famotidine and TMC278, a next generation non-nucleoside reverse transcriptase inhibitor (NNRTI), in HIV-negative volunteers. Abstract TUPDB01, presented at the Fourth International AIDS Society Conference on HIV Pathogenesis, July 22-25, 2007, Sydney, Australia.
36. Vanveggel S, Buelens A, Crauwels H, et al. TMC278 $25 \mathrm{mg}$ qd has no effect on corrected QT interval in a study in HIV-negative volunteers. Abstract PE7.1/2, presented at the 12th European AIDS Conference, November 11-14, 2009, Cologne, Germany.

37. Desmidt M, Willems B, Dom P, et al. Absence of a teratogenic potential from a novel next generation NNRTI, TMC278. Abstract PE7.1/4 presented at 12th European AIDS Conference, November 11-14, 2009, Cologne, Germany.

38. Pinheiro E, Vasan A, Kim JY, et al. Examining the production costs of antiretroviral drugs. AIDS. 2006;20(13):1745-1752.

39. Campaign for Essential Medicines. Untangling the Web of Antiretroviral Price Reduction. 13th ed. Geneva, Switzerland: Medecins Sans Frontieres; 2010. Available at: http://utw.msfaccess.org/background/ aids_progress_under_siege. Accessed March 4, 2011.

40. Johnson \& Johnson. Tibotec signs multiple agreements with generic manufacturers to provide access to new HIV treatment. Available at: http://www.jnj.com/connect/news/all/Tibotec-Signs-MultipleAgreements-with-Generic-Manufacturers-to-Provide-Access-to-NewHIV-Treatment. Accessed March 30, 2011.

41. World Health Organization. Towards universal access: Scaling up priority HIV/AIDS interventions in the health sector. Progress report. Geneva, Switzerland: WHO/UNAIDS/UNICEF; 2009.

42. World Health Organization. Updated List of Missing Drug Formulations for HIV Treatment to be Reviewed by the WHO 18th Expert Committee on the Selection and Use of Essential Medicines. Available at: http://www.who.int/selection_medicines/committees/expert/18/policy/ Missing_HIV_formulations.pdf. Accessed March 30, 2011.

43. Grant RM, Lama JR, Anderson PL, et al. Preexposure chemoprophylaxis for HIV prevention in men who have sex with men. $N$ Engl J Med. 2010;363(27):2587-2599.

44. Grohskopf L, Gvetadze R, Pathak S, et al. Preliminary analysis of biomedical data from the Phase II clinical safety trial of tenofovir disoproxil fumarate (TDF) for HIV-1 pre-exposure prophylaxis (PrEP) among US men who have sex with men (MSM). Abstract FRLBC102, presented at the XVIII International AIDS Conference, July 18-23, 2010, Vienna, Austria.

45. Abdool Karim Q, Abdool Karim SS, Frohlich JA, et al. Effectiveness and safety of tenofovir gel, an antiretroviral microbicide, for the prevention of HIV infection in women. Science. 2010;329(5996):1168-1174.

46. Gostin LO, Kim SC. Ethical allocation of preexposure HIV prophylaxis. JAMA. 2011;305(2):191-192.
HIV/AIDS - Research and Palliative Care

\section{Publish your work in this journal}

HIV/AIDS - Research and Palliative Care is an international, peerreviewed open-access journal focusing on advances in research in HIV, its clinical progression and management options including antiviral treatment, palliative care and public healthcare policies to control viral spread. The journal welcomes original research, basic science,

\section{Dovepress}

clinical \& epidemiological studies, reviews \& evaluations, expert opinion \& commentary, case reports \& extended reports. The manuscript management system is completely online and includes a very quick and fair peer-review system. Visit http://www.dovepress.com/ testimonials.php to read real quotes from published authors. 